\title{
Assessment of cancer care in Indian elderly cancer patients: A single center study
}

\author{
Anindya Sarkar, UP Shahi'
}

\begin{abstract}
Background and purpose: This prospective study aimed to assess the profiles of elderly cancer patient to optimize cancer care in Indian setup. The profiles have been compared with that of younger patients in terms of epidemiological, clinical data, co-morbidity, treatment, toxicity, clinical outcome, and survival pattern. Materials and Methods: The study comprised cancer patients attending radiotherapy outdoor (November 2005 to June 2006). There were 104 patients of age $\geq 60$ years (elderly group) and $12 \mathrm{I}$ patients of 45-59 years (younger group). Results: Elderly group had median age 65 years (60-88 years) with M:F = I:I. The younger group had median age 50 years (45-59 years) with $\mathrm{M}: \mathrm{F}=1: 2$. Elderly had higher proportion of gastrointestinal and genito-urinary tract malignancies.Younger group had higher proportion of breast, lymphoma, and brain tumor. I 3\% had co-morbidity, $50 \%$ received treatment, $27 \%$ were treated with radiotherapy with or without surgery, and two-third of these cases belong to elderly group. Majority tolerated treatment well. $10 \%$ had significant grade of toxicity. $57 \%$ of elderly patients did not accept and one-fourth of all cases did not complete the prescribed treatment. $88 \%$ cases were responders of which $70 \%$ showed complete response. There were no differences between two groups. At 12 months 35\% of treated patients came for follow-up. At first 12 months, $60-70 \%$ were alive without disease. Conclusion: There were differences between two groups in terms of performance status, treatment acceptance, and treatment modality prescribed. Elderly patients deserve same opportunity as younger patients for treatment and survival options from the oncologist.
\end{abstract}

Key words: Cancer care optimization, comparison of profiles, Indian elderly and younger cancer patients, geriatric, elder

\section{Introduction}

India is witnessing a demographic transformation from a younger society to a mature one. India had about 76 million elderly people, thus constituting $7.6 \%$ of the total population in 2001. By the year 2020, India will have $11 \%$ of the population in the age group of 60 years and above. By this time the projected elderly population will cross the billion mark all over the world. Due to improvement in public health, now more individuals are living longer and the proportion of those living beyond 60 years has increased significantly and will increase further over the next 20 years. The incidence of cancer increases with age and more than $12-23 \%$ of all cancers occur after the age of 65 years (NCCP 2002, NCRP 2001). ${ }^{[2,16]}$ Although more than $25 \%$ of cancers are diagnosed in people over 60 year, this group is less extensively investigated and probably receives less appropriate treatment than younger patients. Usually, the elderly cancer patients are considered not suitable for a curative treatment approach. The choice of

Department of Radiotherapy, North Bengal Medical College, Siliguri, 'IMS, Banaras Hindu University, Varanasi, India

Correspondence to: Dr.Anindya Sarkar,

E-mail: asarkardr@yahoo.co.in

\begin{tabular}{|l|l|}
\hline \multicolumn{2}{|c|}{ Access this article online } \\
\hline Quick Response Code: & Website: \\
\hline
\end{tabular}

treatment modalities in term of radiotherapy, chemotherapy, or even surgery becomes a difficult decision both for the doctor and patients and their relatives. More often elderly patients are put on conservative or less aggressive treatment. Thus, a large proportion of patients are denied the benefit of aggressive treatment.

Moreover, many of the prospective clinical trials have excluded this group of patients from the trials, and thus, no worthwhile clinical studies were forthcoming from this age group, especially in Indian setup.

Therefore, in view of the above, there seems a be a need to integrate and optimize treatment planning for elderly cancer patients to achieve an improved tumor control, quality of life, and survival with better health care. This study aimed to assess the profile of diagnosis, treatment, and survival of elderly cancer patient in order to optimize cancer care for this group.

\section{Materials and Methods}

This prospective study comprised patients with histologically proven malignancy attending the Radiotherapy Department of Institute of Medical Sciences, Banaras Hindu University, during the period November 2005 to June 2006. These patients were examined clinically and with requisite investigations (e.g., hematological, biochemical, and imaging) to have assessment of the extent of disease. The attendants of the patients were subjected to a counseling session regarding nature of disease, treatment options, and prognosis. All the patients were assessed by taking (a) detailed history (b) complete general physical examination. Performance was determined as per ECOG scale. 
Biochemical, hematological, and radiological investigations were performed before actual treatment started, during treatment, and follow-up. Most of the patients already presented with histopathology report. Rest were referred for histopathological examination and some were referred for review of pathological diagnosis to Department of Pathology, IMS, BHU. Clinical staging and grouping were done according to TNM (UICC-AJCC staging) classification. Co-morbid disease (s) were searched by detailed history, complete general physical examination, and required biochemical, hematological, and radiological investigations, viz. blood pressure, ECG, echocardiography, color doppler, blood sugar, joint X-rays, ultrasound (abdomen + pelvis), etc., Detected co-morbid conditions were treated accordingly by respective specialized doctor.

Based on ECOG performance status, site of the disease, stage, and affordability, patients were treated either with combined chemotherapy and radiotherapy or radiotherapy alone. Drugs used were cyclophosphamide, methotrexate, 5-flurouracil, doxorubicin, cisplatinum, paclitaxel, etc., as per the chemotherapy schedule chosen. Care was taken for proper drug route selection, preparation of the patient, pre-treatment evaluation, assessment of hematological, clinical, and other parameters. Patients were monitored post-treatment to detect any toxicity.

Radiotherapy was delivered using appropriate portals, radiotherapy planning on simulator, and treatment planning system by ${ }^{60} \mathrm{Co}$ teletherapy unit (Phoenix or Theratron 780E). Gynecological cancers were also treated with appropriate brachytherapy procedure (Intracavitary application) on after loading units (manual and remote).

Toxicity monitoring was done. Gastrointestinal (GI) toxicity, skin, and mucosal reaction were noted and graded according to World Health Organization (WHO) common toxicity criteria. Definitions of complete and partial response and progressive disease were based on the standardized response definitions of the WHO. Patients were advised to come for follow-up on a monthly basis for one year and thereafter two monthly. For overall survival (OS), disease free survival (DFS) the time was taken from the date of registration to time of event. All lost to follow-up patients were taken as diseased and dead regardless of status (worst case scenario). Observations made were subjected to determination of $P$ value, Chi-square test, student $t$-test, mean, and median value accordingly by SPSS 16.0.2 statistical tool.

\section{Results}

\section{Epidemiological profiles}

Elderly group comprised 28\% (104/369) and younger group comprised 33\% (121/369) of total new cancer cases $(n=369)$. The median age in elderly group was 65 years (range 60-88 years) and in younger group was 50 years (range 45-59 years). In elderly group, majority of cases were between age group 60 and 64 years (39\%).
In younger group, majority of cases was between age group 40 and 49 years (41\%). In elderly group, cancer affected both sexes equally, whereas $66 \%$ of female were affected in younger group. This difference was statistically significant $\left[P<0.05\right.$, Chi-square $\left(\chi^{2}\right)=6.005$, degree of freedom $($ d.f $)=1$ ] [Table 1a]. Overall females outnumbered males from age 45 to 69 years. Thereafter the ratio was reversed, males dominating the age group of 70 years or above. Maximum numbers of patients in both groups were Hindus. In elderly group, $73 \%$ were from rural areas and $27 \%$ were from urban areas. In younger group, 65\% were from rural areas and 35\% were from urban area. In both the groups, majority of patients belonged to low income group and poor socio-economic status $(70 \%$ and $78 \%$ in elderly and younger, respectively). In elderly group, 79\% were Illiterate and $9 \%$ received education up to primary school. In younger group, 74\% were illiterate and 18\% received education up to primary school. Epidemiological profiles are given in Tables $1 \mathrm{a}$ and $1 \mathrm{~b}$.

\section{Clinical profiles}

Majority of cases (75\% in elderly and $87 \%$ in younger group) were in good performance status ( 0 or 1$)$. However,

Table 1a: Epidemiological profiles

\begin{tabular}{lcccc}
\hline Age (years) & $\begin{array}{c}\text { Total } \\
\text { no }(\%)\end{array}$ & $\begin{array}{c}\text { Male } \\
\text { no }(\%)\end{array}$ & $\begin{array}{c}\text { Female } \\
\text { no }(\%)\end{array}$ & $\begin{array}{c}\text { Male: } \\
\text { Female }\end{array}$ \\
\hline $45-49$ & $49(22)$ & 17 & 32 & $1: 1.9$ \\
$50-54$ & $45(20)$ & 16 & 29 & $1: 1.8$ \\
$55-59$ & $27(12)$ & 8 & 19 & $1: 2.4$ \\
$60-64$ & $41(18)$ & 18 & 23 & $1: 1.3$ \\
$65-69$ & $28(13)$ & 10 & 18 & $1: 1.8$ \\
$70-74$ & $21(9)$ & 13 & 8 & $1.6: 1$ \\
$75-79$ & $9(4)$ & 7 & 2 & $3.5: 1$ \\
$\geq 80$ & $5(2)$ & 4 & 1 & $4: 1$ \\
\hline$P$
\end{tabular}

$P<0.05$, Chi quare $\left(\chi^{2}\right)=6.005$, degree of freedom $($ d.f $)=1$

Table 1b: Epidemiological profiles

\begin{tabular}{lccc}
\hline & $\begin{array}{c}\text { Elderly } \\
(N=104)\end{array}$ & $\begin{array}{c}\text { Younger } \\
(N=121)\end{array}$ & $\begin{array}{c}\text { Total } \\
(N=225)\end{array}$ \\
\hline Sex & & & \\
$\quad$ Total male \% & 50 & 34 & 41 \\
$\quad$ Total female \% & 50 & 66 & 59 \\
Religion & & & \\
$\quad$ Hindu & $95(91)$ & $116(96)$ & $211(94)$ \\
$\quad$ Muslim & $9(9)$ & $5(4)$ & $14(6)$ \\
Inhabitance & & & \\
$\quad$ Rural & $76(73)$ & $79(65)$ & $115(69)$ \\
$\quad$ Urban & $28(27)$ & $42(35)$ & $70(31)$ \\
Education & & & \\
$\quad$ Illiterate & $56(79)$ & $75(74)$ & $131(76)$ \\
$\quad$ Primary school & $6(9)$ & $18(18)$ & $24(14)$ \\
$\quad$ High school & $6(9)$ & $4(4)$ & $10(6)$ \\
$\quad$ College & $3(3)$ & $4(4)$ & $7(4)$ \\
Family income (Rs/month) & & & \\
$\quad<6000$ & $60(70)$ & $91(78)$ & \\
$\geq 6000$ & $25(30)$ & $25(22)$ & \\
\hline
\end{tabular}


$25 \%$ of elderly patients and $13 \%$ of younger patients had poorer performance status of 2 or more $(P<0.001$, $\chi^{2}=10.9558$, d.f $=1$ ). In elderly group, $43 \%$ patients and in younger group $55 \%$ patients had body weight between 40 and $49 \mathrm{~kg}$. In elderly group, $76 \%$ and in younger group $75 \%$ had hemoglobin level $\geq 10$ gm $\%$ [Table $2 \mathrm{a}$ ].

Majority of cancer belonged to female genitalia, head and neck region, GI tract, genitor-urinary tract, breast, lymphoma, brain tumor, sarcoma, and lung. Site-wise common cancers were cervix, gall bladder, larynx, urinary bladder, lymphoma, stomach, colorectal, prostate, anal canal, and breast. Elderly patients had relatively higher proportion of GI and genito-urinary tract malignancies. Younger group had higher proportion of breast, lymphoma, and brain tumor. Uterine cervix was the most common site overall in both groups. However, younger had proportionately higher number of cancer cervix cases [Table 2d].

Histopathologically, majority of cases were carcinomas of which two-third were squamous cell carcinoma and one-third were adenocarcinoma [Table 2b]. In elderly and younger groups, proper disease staging was possible in $57 \%$ and $48 \%$ patients, respectively [Table 3a]. Proper staging was not possible because patient defaulted after being advised the necessary investigations or financial constraints causing inability to do MRI, CT Scan, PET CT,

Table 2a: Clinical profiles

\begin{tabular}{lcc}
$\begin{array}{l}\text { Hemoglobin } \\
(\mathrm{gm} \%)\end{array}$ & $\begin{array}{c}\text { Elderly }(n=54) \\
\text { no }(\%)\end{array}$ & $\begin{array}{c}\text { Younger }(n=69) \\
\text { no }(\%)\end{array}$ \\
\hline$<10 \mathrm{gm} \%$ & $13(24)$ & $17(25)$ \\
$\geq 10 \mathrm{gm} \%$ & $41(76)$ & $52(75)$ \\
\hline ECOG PS & $\begin{array}{c}\text { Elderly }(n=104) \\
(\%)\end{array}$ & $\begin{array}{r}\text { Younger }(n=121) \\
\end{array}$ \\
\hline 0 & $37(36)$ & $33(27)$ \\
1 & $40(39)$ & $72(60)$ \\
$\geq 2$ & $27(25)$ & $16(13)$ \\
\hline
\end{tabular}

ECOG PS=Eastern cooperative oncology group performance status $(P<0.001$, $\chi^{2}=10.9558$, d.f $\left.=1\right)$

Table 2b: Histopathological types

\begin{tabular}{lccc}
\hline Histology & $\begin{array}{c}\text { Elderly }(n=104) \\
\text { no }(\%)\end{array}$ & $\begin{array}{c}\text { Younger }(n=121) \\
\text { no }(\%)\end{array}$ & $\begin{array}{c}\text { Total }(n=225) \\
\text { no }(\%)\end{array}$ \\
\hline Carcinoma & & & \\
$\quad$ Squamous & $45(43)$ & $66(55)$ & $111(49)$ \\
Adeno & $33(32)$ & $26(21)$ & $59(26)$ \\
Others & $17(17)$ & $15(13)$ & $32(14)$ \\
Sarcoma & $1(1)$ & $4(3)$ & $5(3)$ \\
Lymphoma, & $6(6)$ & $6(5)$ & $12(5)$ \\
myeloma & & & $5(3)$ \\
Brain tumor & $1(1)$ & & $5(3)$ \\
\hline
\end{tabular}

endoscopy, etc., In elderly group, 39\% were stage IV and $36 \%$ were stage III. In younger group, 36\% were stage IV and $42 \%$ were stage III [Table $3 \mathrm{a}$ ].

Overall thirteen percent of patients had associated co-morbid conditions like hypertension, heart disease, diabetes, cholilithiasis, and arthritis [Table 2c]. There were no differences in both the groups.

\section{Treatment and toxicity profiles}

In elderly group, $43 \%$ received treatment, of which $73 \%$ completed treatment and 27\% not completed. 57\% either refused treatment or left against medical advice (LAMA). In younger group, 53\% received treatment, of which $75 \%$ completed treatment and 25\% not completed. $47 \%$ either refused treatment or LAMA, although this difference was not statistically significant $\left(P>0.05, \chi^{2}=2.074\right.$, d.f $\left.=1\right)$ [Table 3b,c].

In elderly group, $40 \%$ cases received chemotherapy, radiotherapy, with or without surgery, whereas in younger group $67 \%$ cases received chemotherapy, radiotherapy, with or without surgery. In elderly group, $42 \%$ cases received radiotherapy with or without surgery, whereas in younger group $16 \%$ cases received radiotherapy with or without surgery and this was statistically significant difference [Table $3 \mathrm{~d}$ ] $(P<0.01$, $\chi^{2}=10.52$, d.f $=2$ ). In elderly group, $38 \%$ received single modality treatment of which $12 \%$ received surgery alone, $76 \%$ received radiotherapy alone, and $12 \%$ received chemotherapy alone. In younger group, $25 \%$ received single modality treatment of which $25 \%$ received surgery alone, $37.5 \%$ received radiotherapy alone, and $37.5 \%$ received chemotherapy alone. In elderly group, $28 \%$ showed grade 2 or more GI toxicity. In younger group, $15 \%$ showed grade 2 or more GI toxicity $\left(P>0.05, \chi^{2}=2.69\right.$, d.f $\left.=3\right)$ statistically not significant [Table 4].

\section{Clinical outcome}

In elderly group, 57\% showed complete response (CR), $24 \%$ showed partial response (PR), 3\% showed no response (NR), and 16\% showed progressive disease (PD). In younger group, 65\% showed CR, 28\% showed PR, $2 \%$ showed NR, 5\% showed PD $\left(P>0.05, \chi^{2}=2.9686\right.$, d.f $=3$ ) [Table 5], so difference in response rate in both the groups were statistically not significant. Overall response rate was $60 \%(27 / 45)$ in elderly and 67\% (43/64) in younger groups [Table 5].

In elderly group, $82 \%$ patients attended follow-up in first month and $34 \%$ at 12 months. In younger group, $72 \%$ patients attended follow-up in first month and $35 \%$ at 12 months. At 12 months, follow-up in elderly group

Table 2c: Co-morbid diseases

\begin{tabular}{llccccc}
\hline & & Diabetes & Tuberculosis & Hypertension/CHD & Arthritis & Choleli-thiasis \\
\hline Elderly & Total 15(14.4) & $5(4.8)$ & $3(2.9)$ & $3(2.9)$ & $2(1.9)$ & $2(1.9)$ \\
Younger & Total 14(11.6) & $4(3.3)$ & 0 & $7(5.8)$ & 0 & $3(2.5)$ \\
\hline
\end{tabular}


Table 2d: Distribution according to primary site of disease

\begin{tabular}{|c|c|c|c|c|c|c|}
\hline \multirow[t]{2}{*}{ Primary sites } & \multicolumn{2}{|c|}{ Male } & \multicolumn{2}{|c|}{ Female } & \multicolumn{2}{|c|}{ Total } \\
\hline & $\begin{array}{l}\text { Younger } \\
(N=41) \\
\text { no }(\%)\end{array}$ & $\begin{array}{l}\text { Elderly } \\
(N=52) \\
\text { no }(\%)\end{array}$ & $\begin{array}{c}\text { Younger } \\
(N=\mathbf{8 0 )} \\
\text { no }(\%)\end{array}$ & $\begin{array}{l}\text { Elderly } \\
(N=52) \\
\text { no }(\%)\end{array}$ & $\begin{array}{c}\text { Younger } \\
(N=121) \\
\text { no }(\%)\end{array}$ & $\begin{array}{c}\text { Elderly } \\
(N=104) \\
\text { no }(\%)\end{array}$ \\
\hline Head and Neck & & & & & $15(12)$ & 19 (18) \\
\hline Oral cavity & 6 & 9 & 2 & 0 & $8(7)$ & $9(8)$ \\
\hline Oropharynx & 3 & 1 & 0 & 0 & $3(2)$ & $1(1)$ \\
\hline Larynx & 0 & 4 & 1 & 2 & 1 & $6(6)$ \\
\hline Others & 2 & 3 & 1 & 0 & $3(2)$ & $3(3)$ \\
\hline Female genitalia & - & - & $50(63)$ & $29(56)$ & $50(41)$ & $29(28)$ \\
\hline Cervix & - & - & $44(55)$ & $26(50)$ & $44(36)$ & $26(25)$ \\
\hline Endometrial & - & - & $1(1.9)(1.2)$ & 2 & $1(0.8)$ & 2 \\
\hline Vagina & - & - & 1 & 0 & 1 & 0 \\
\hline Vulva & - & - & 1 & 0 & 1 & 0 \\
\hline Ovary & - & & $3(5.8)$ & 1 & $3(2.5)$ & 1 \\
\hline Breast & $2(12)$ & 0 & $9(18)$ & 3 & $11(9)$ & $3(3)$ \\
\hline GI Tract & 7 & 11 & 13 & 11 & $20(17)$ & $22(21)$ \\
\hline Esophagus & 1 & 1 & 1 & 0 & 2 & 1 \\
\hline Stomach & 1 & 2 & 1 & 2 & 2 & 4 \\
\hline Colorectal & 0 & 2 & 2 & 2 & 2 & 4 \\
\hline Anal canal & 1 & 3 & 1 & 0 & 2 & 3 \\
\hline Gall bladder & 3 & 1 & 8 & 6 & $11(9)$ & $7(7)$ \\
\hline Liver & 1 & 1 & 0 & 1 & 1 & 2 \\
\hline Genito-urinary & & & & & $2(1.5)$ & $11(11)$ \\
\hline Urinary bladder & 0 & 6 & 1 & 0 & 1 & $6(60)$ \\
\hline Prostate & 0 & 4 & - & - & 0 & $4(40)$ \\
\hline Kidney & 0 & 0 & 0 & 0 & 0 & 0 \\
\hline Penis & 1 & 1 & - & - & 1 & 1 \\
\hline Lung & 2 & 1 & 1 & 1 & $3(2.5)$ & $2(1.9)$ \\
\hline NHL/Hodgkin's lymphoma/myeloma & 3 & 3 & 3 & 3 & $6(5)$ & $6(4)$ \\
\hline Soft-tissue sarcoma & 1 & 1 & 3 & 0 & $4(3.3)$ & $1(0.96)$ \\
\hline Brain tumor & 4 & 1 & 0 & 0 & $4(3.3)$ & $1(0.96)$ \\
\hline Miscellaneous & 4 & 7 & 1 & 4 & $5(4)$ & $11(10)$ \\
\hline
\end{tabular}

Table 3a: Clinical profiles: Stage at presentation

\begin{tabular}{lcccc}
\hline & Stage I & Stage II & Stage III & Stage IV \\
\hline $\begin{array}{l}\text { Elderly }(n=59) \\
\text { no }(\%)\end{array}$ & $4(7)$ & $11(18)$ & $21(36)$ & $23(39)$ \\
$\begin{array}{l}\text { Younger }(n=8) \\
\text { no (\%) }\end{array}$ & $2(3)$ & $11(19)$ & $24(42)$ & $21(36)$ \\
\hline
\end{tabular}

Table 3b: Treatment profiles: Treatment acceptance

\begin{tabular}{lccc}
\hline $\begin{array}{l}\text { Treatment } \\
\text { profile }\end{array}$ & $\begin{array}{c}\text { Elderly }(n=104) \\
\text { no }(\%)\end{array}$ & $\begin{array}{c}\text { Younger }(n=121) \\
\text { no }(\%)\end{array}$ & $\begin{array}{c}\text { Total }(n=225) \\
\text { no }(\%)\end{array}$ \\
\hline Received & $45(43)$ & $64(53)$ & $109(48)$ \\
LAMA/ & $59(57)$ & $57(47)$ & $116(52)$ \\
Refused & \multicolumn{4}{l}{} \\
\hline LAMA=Left against medical advice; $\left(P>0.05, \chi^{2}=2.074\right.$, d.f (degree of freedom $\left.)=1\right)$
\end{tabular}

cases had $22 \%$ disease-free status and $13 \%$ was alive with disease. At 12 months follow-up in younger group cases had 33\% disease-free status and 3\% was alive with disease. In both elderly group and younger group, median follow-up was 10 months.

\section{Discussion}

It is projected that by 2020 , the population of elderly
Table 3c: Treatment profiles: Treatment compliance

\begin{tabular}{lccc}
$\begin{array}{l}\text { Treatment } \\
\text { profile }\end{array}$ & $\begin{array}{c}\text { Elderly }(n=45) \\
\text { no }(\%)\end{array}$ & $\begin{array}{c}\text { Younger }(n=64) \\
\text { no }(\%)\end{array}$ & $\begin{array}{c}\text { Total }(n=109) \\
\text { no }(\%)\end{array}$ \\
\hline Complete & $33(73)$ & $48(75)$ & $81(74)$ \\
Incomplete & $12(27)$ & $16(25)$ & $28(26)$ \\
\hline
\end{tabular}

Table 3d: Treatment profiles: Type of treatment

\begin{tabular}{lccc}
\hline Type of treatment & $\begin{array}{c}\text { Elderly } \\
(\boldsymbol{n}=\mathbf{4 5})\end{array}$ & $\begin{array}{c}\text { Younger } \\
(\boldsymbol{n}=\mathbf{6 4})\end{array}$ & $\begin{array}{c}\text { Total } \\
(\boldsymbol{n}=\mathbf{1 0 9 )}\end{array}$ \\
\hline $\mathrm{CT}$ and RT both $\pm \mathrm{SX}$ & $18(40)$ & $43(67)$ & $61(56)$ \\
$\mathrm{RT} \pm \mathrm{SX}$ & $19(42)$ & $10(16)$ & $29(27)$ \\
$\mathrm{CT} \pm \mathrm{SX}$ & $6(13)$ & $7(11)$ & $13(12)$ \\
Surgery alone & $2(5)$ & $4(6)$ & $6(5)$ \\
\hline $\begin{array}{l}\text { CT=Chemotherapy; RT=Radiotherapy, SX=Surgery; }\left(P<0.01, \chi^{2}=10.52,\right. \\
\text { statistically significant, d.f }=2)\end{array}$
\end{tabular}

globally would be more than 700 million with two-third belonging to the developing countries. The scenario will be similar in India. By the year 2020, India will have $11 \%$ of the population in the age group of 60 years and above. In the coming decades, a longer life expectancy will lead to a higher cancer burden for elderly people. Moreover, under representation and under treatment of 
Table 4: Toxicity profiles

\begin{tabular}{lcccc}
\hline Toxicity & Grade 0+I & Grade II & Grade III & Grade IV \\
\hline $\begin{array}{l}\text { Elderly }(n=39) \\
\text { no }(\%)\end{array}$ & $28(71.7)$ & $7(17.9)$ & $1(2.5)$ & $3(7.7)$ \\
$\begin{array}{l}\text { Younger }(n=61) \\
\text { no }(\%)\end{array}$ & $52(85)$ & $3(4.9)$ & $4(6.5)$ & $2(3.3)$ \\
\hline$\left(\mathrm{P}>0.05, \chi^{2}=2.69\right.$, d.f $\left.=3\right)$ & & &
\end{tabular}

Table 5: Treatment response

\begin{tabular}{lcccc}
\hline $\begin{array}{l}\text { Treatment } \\
\text { response }\end{array}$ & $\begin{array}{c}\text { Complete } \\
\text { response }\end{array}$ & $\begin{array}{c}\text { Partial } \\
\text { response }\end{array}$ & $\begin{array}{c}\text { No } \\
\text { response }\end{array}$ & $\begin{array}{c}\text { Progressive } \\
\text { disease }\end{array}$ \\
\hline $\begin{array}{l}\text { Elderly } \\
(n=37) \text { no (\%) }\end{array}$ & $21(57)$ & $9(24)$ & $1(3)$ & $6(16)$ \\
$\begin{array}{l}\text { Younger } \\
(n=46) \text { no (\%) }\end{array}$ & $30(65)$ & $13(28)$ & $1(2)$ & $2(5)$ \\
\hline$\left(P>0.05, \chi^{2}=2.9686\right.$, d.f $\left.=3\right)$ & & &
\end{tabular}

elderly cancer patients is an alarming issue which has not been investigated sufficiently till date particularly in Indian cancer patients. Therefore, this study was aimed to assess profiles of elderly cancer patients and to compare these profiles with younger cancer patients. The study included a total 225 patients in the age $\geq 45$ years over an 8 month period and these patients were divided into two age groups - younger (45-59 years) and elderly ( $\geq 60$ years). Elderly group comprised $28 \%$ of total new cases which are comparable with national and international references. ${ }^{[16,24]}$ Sex ratio, religion, inhabitance, and educational statuses all are similar with our national data ${ }^{[2,16]}$ reflecting the picture of a developing country. Female preponderance in younger group is due to large number of cancer cervix patients $(36 \%)$ in this study. Elderly males and younger females were more anemic.

In the younger group, female genital cancer was more than elderly (63\% vs. $56 \%$ ). This is due to greater number of female patients in younger $(\mathrm{M}: \mathrm{F}=1: 2)$. Cancer cervix is less in elderly than younger (25\% vs. 36\%). NCRP, 1996 data shows similar presentation. Head and neck cancer patients were more in elderly than younger $(18 \%$ vs. 12). This is again due to more number of females in younger group $(\mathrm{M}: \mathrm{F}=1: 2)$. Cancer larynx is more common in elderly than the younger ( $6 \%$ vs. $1 \%)$. Cancer tongue is more common in elderly. Recent data show cancer tongue has maximum incidence, followed by hypo pharynx and larynx and all these cancers were more common in elderly patients ( $\geq 60$ years). ${ }^{[16]} \mathrm{GI}$ tract malignancies were commoner in elderly than younger (21\% vs. 17\%). Colorectal cancer was more common in elderly (33\% vs. $25 \%)$. Similar data noted in literature. ${ }^{[20,24,29]}$ Carcinoma gall bladder less in elderly in contrast to national and international data. Peak age incidence of cancer (CA) gall bladder is in seventh and eight decade. ${ }^{[16]}$ Median age of CA gall bladder is 62 years with a range of 42-96 years. ${ }^{[35]}$ Therefore, present data suggest a significant occurrence of CA gall bladder in younger group. CA urinary bladder and CA prostate were predominantly found in elderly group. ${ }^{[16,24]}$ Lymphoma and myeloma were marginally higher in elderly group. These data match with both NCRP, 1996 (Mumbai data) and SEER cancer statistic review (1975-2003). Breast cancer was found to be lesser in elderly than younger group (3\% vs. 9\%). Mumbai data from NCRP, 1996, show slightly higher number in younger patients ${ }^{[16]}$ (45-59 years). Brain tumor and soft-tissue sarcoma were found more in younger patients ( $3 \%$ vs. $1 \%$ each). Findings were similar found in NCRP, 1996 $6^{[2,16]}$ and SEER cancer statistic review (1975-2003). ${ }^{[24]}$ Commoner cancers in younger patients were CA cervix (36\%), CA gall bladder (9\%), CA breast $(9 \%)$, brain tumor $(3.3 \%)$, soft tissue sarcoma $(3.3 \%)$ etc., than elderly. Commoner cancer in elderly were CA larynx $(6 \%)$, CA colorectum (4\%), CA urinary bladder $(6 \%)$, CA prostate (4\%), lymphoma and myeloma (4\%) etc., than younger cancer patients, (

In both the groups, majority of patients presented with advanced stage, i.e., stage III and stage IV combined $75 \%$ vs. $78 \%$ (elderly group vs. younger group), which matches with the national data, $70 \%$ present in the clinically advanced stages T3-T4. ${ }^{[2,6]}$

In elderly group, median age of the patients with co-morbidity was 70 years and among them 33\% refused treatment. $33 \%$ patients were treated only by radiation. Only $13 \%$ received chemotherapy and these patients showed grade 3 and grade 4 GI toxicity. In younger group, median age of the patients with co-morbidity was 50 years and $67 \%$ refused treatment. Rest received chemotherapy and radiotherapy in equal proportion (18\% each) with equal toxicity. Therefore, co-morbidity plus age may have an impact on treatment modality and treatment tolerance although other factors (advanced stage and poor performance status) may be related. Various studies showed that co-morbidities in cancer patients have impact in clinical decision making, treatment strategies, chemotherapy-related toxicity, and effectiveness of treatment. ${ }^{[9,10,19,30-35]}$ However, co-morbidity need not be a barrier to inclusion of cancer patients in a study. Studies in elderly patients with high incidences of co-morbidities have been completed successfully. ${ }^{[1]}$ In this study, top three co-morbid conditions were hypertension, CHD, and diabetes similar with NAI/NCI, 1997 data - hypertension, heart-related conditions, and arthritis top the list. ${ }^{[21,23]}$

In elderly group more patients refused treatment than in the younger group (57\% vs. 47\%). Various studies shows elderly cancer patients were under represented and under treated. ${ }^{[4,5,7]}$ Few elderly patients enter trials, not all receive treatment. ${ }^{[28]}$ The higher likelihood of not receiving standard therapy, the representation of older patients in clinical trials has been poorly evaluated. ${ }^{[11]}$ Elderly were under-represented in the registration trials of new cancer therapies. ${ }^{[27]}$ Possible explanation of under representation and less acceptance of definitive treatment in elderly group may include lack of appropriate trials, study-imposed 
restrictions, high burden of co-morbidity, and physician attitudes. ${ }^{[21,25]}$ and knowledge, patient preferences, and social, geographic, or financial barriers [A recent Southwest Oncology Group (SWOG) study].

In elderly group, lesser number of patients received radiotherapy along with chemotherapy (concurrent, neoadjuvant, or adjuvant) than younger group (40\% vs. 67\%), and more patients were treated by radiotherapy (radiotherapy alone or postoperative radiotherapy) than younger (42\% vs. 16\%). This difference was statistically significant $\left(P<0.01, \chi^{2}=10.52\right.$, d.f $=2$ ). Median age of elderly group patients who received only radiotherapy was higher than the patients who received radiotherapy along with chemotherapy (70 years vs. 62 years).

In elderly group who received radiotherapy plus chemotherapy had completed treatment more than who received radiotherapy only (62\% vs. 90\%). Other parameters like presentation of stage, toxicity, and response were comparable in both the groups. Only treatment compliance varied significantly in between patients who received radiotherapy plus chemotherapy and radiotherapy only. Therefore, in elderly cancer patients age should not be a barrier and all patients should not be automatically offered conservative or inadequate treatment. Patients who received radiotherapy plus chemotherapy had shown less compliance but similar toxicity and response as who received radiotherapy only. Less compliance to chemotherapy and radiotherapy both in elderly patients was neither age nor toxicity of chemotherapy (). It may be due to unwillingness of patients or his attendant, poor socio-economic status (poverty, illiteracy, cost of anticancer drugs, etc.) or associated disease conditions. Treating physician also sometimes hesitate to treat older patients by full treatment with a curative intent. Practically no significant difference was found in elderly group and younger group in terms of performance status, presenting stage, treatment toxicity, and stage-wise response. Even treatment compliance shows comparable result both in elderly and younger groups. Again socio-economic status, cost of drugs, etc., may explain the non acceptance of treatment of elderly cancer patients.

Various studies also support that elderly patients should not be under treated. Treatment tolerance and toxicities were also not a barrier for cancer treatment and cancer trials in elderly. ${ }^{[3,13,17,18,22,26]}$ Age alone should not be a contraindication to the use of optimal chemotherapy regimens in older women who were in good general health. ${ }^{[8,15]}$

\section{Treatment response assessment}

Stage by stage comparison of treatment response shows comparable response rate in both elderly group and younger group except in stage IV disease in which younger group shows better response rate than elderly group
(57\% vs. 20\%). (No elderly patients with stage IV disease came to follow up.

\section{Follow-up and survival}

In younger group, 72\% (46/64) patients attended outdoor for their first follow-up visit. In elderly group, 82\% (37/45) attended outdoor for their first follow-up visit. In younger group, $35 \%$ followed up for $\geq 12$ months. In elderly group, 34\% followed up for 12 months or more. In both elderly group and younger group, median follow-up was 10 months. Among the patients who followed up at 12 months, 63\% were disease free in elderly group and 91\% were disease free in younger group. (should be part of the results-in the discussion, only include your comments and conclusions-and compare to the published literature).

Therefore, it can be opined there was no much difference in follow-up pattern in both the groups and almost 65\% cancer patients lost to follow-up after one year of first visit in our study. Monfardini et al., showed there was no evidence that excess toxicity was an obstacle to treatment continuation for elderly patients, whereas treatment discontinuation did occur for the older age group more frequently because of loss to follow-up and treatment refusal. ${ }^{[13,14]}$

\section{Summary and Conclusion}

Cancer in elderly is a major problem. There appears to be similarity between younger and elderly groups with respect to presentation, stage, religion, inhabitants, socio-economic status, and educational level. Elderly patients presented with poorer performance status and male preponderance. Elderly group had more number of patients belonging to GI tract, and genito-urinary malignancies, whereas younger group had more frequently occurring tumors of lymphoma, sarcoma, brain tumor, and ovary. Younger had higher incidence of carcinoma cervix in comparison to elderly. Other sites had similar distribution. Treatment acceptance was poorer in elderly group; however, treatment compliance was not related to age of patient. Majority of elderly patients are treated by radiotherapy. However, a significant proportion of elderly patients were treated by aggressive approach with combination of chemotherapy, radiotherapy, and surgery and all modalities were well tolerated. Elderly patients responded in similar pattern as compared to younger patients with respect to tumor response, toxicity, follow-up, and disease-free status.

Therefore, based on the findings of present study it may be concluded that elderly patients deserve same opportunity for treatment and survival options from the oncologist. However, there is a need to go for a clinical trial with larger number of patients involving elderly for optimizing cancer care continuum of diagnosis, treatment, and survival.

\section{References}

1. Aapro MS, Köhne $\mathrm{CH}$, Cohen JH, Extermann M. Never too old? Age should not be a barrier to enrollment in cancer clinical trials. Oncologist 2005; 10: 198-4.

2. Agarwal SP, Rao YN, Gupta S. Fifty years of cancer control in India. $1^{\text {st }}$ ed. National Cancer Control Program (NCCP); 2002. p. 41-7. 
3. Susan BR, Muss BH. Adjuvant chemotherapy in the elderly: Whom to treat, what regimen? Oncologist 2006;11:234-42.

4. Carol A, Selby TR, Siu LL. Systematic review of barriers to the recruitment of older patients with cancer onto clinical trials. J Clin Oncol 2005;23:3112-24.

5. Carol T, Pond GR, Peloza B, Kok J, Naidoo K. Analysis of treatment practices for elderly cancer patients in Ontario, Canada. J Clin Oncol 2005;23:3802-10.

6. Dinshaw KA, Nene BM, Prabhakaran PS, Prasad AE. Bangalore population based cancer registry, Bangalore, Kidwai Memorial Institute of Oncology, Bangalore. Individual Registry Data: 1990-1996.

7. Extermann M, Aparo M. Assessment of older cancer patients. Hematol Oncol Clin North Am 2000; 14:63-77.

8. Hilpert F, du Bois A, Greimel ER, Hedderich J, Krause G, Venhoff L, etal. Feasibility, toxicity and quality of life of first-line chemotherapy with platinum/paclitaxel in elderly patients aged 70 years with advanced ovarian cancer-a study by the AGO OVAR Germany. Ann Oncol 2007; 18:282-7.

9. Guralink JM. Assessing the impact of comorbidity in the older population. Ann Epidemiol 1996;6:376-80.

10. Fried LP, Roche BK, Kasper JD, Guralnik JM. Association of comorbidity with disability in older women: The Women Health And Aging Study. J Clin Epedemiol 1999;52:27-37.

11. Karen WL, Joseph LY, Pho LP, Zee B. Enrollment of older patients in cancer treatment trials in Canada: Why is age a barrier? J Clin Oncol 2003;21:1618-23.

12. Kumar A, Soares HP, Balducci L. Treatment tolerance and efficacy in elderly oncology: A systematic review of phase III randomized trials conducted by five National Cancer Institute-Sponsored Cooperative Groups. J Clin Oncol 2007;25: 1272-6.

13. Monfardini S, Sorio R, Boes GH, Kaye S, Serraino D. Entry and evaluation of elderly patients in European Organization for Research and Treatment of Cancer (EORTC) new-drug-development studies. Cancer 1995;76:333-8.

14. Monfardini S. Elderly oncology: A new subspecialty? J Clin Oncol 2004;22:4655.

15. Hyman BM, Woolf S, Berry D, Cirrincione C, Raymond B. For the cancer and leukemia group B: Adjuvant Chemotherapy in older and younger women with lymph node-positive breast cancer. JAMA 2005;293: 1073-81.

16. Nandakumar A. National Cancer Registry Programme (NCRP), Indian Council of Medical Research. August 2001.

17. O'ConnellJ B, Maggard MA, Ko CY. Cancer-directed surgery for localized disease: Decreased use in the elderly. Ann Surg Oncol 2004;11:962-9.

18. Okamoto I, Moriyama E, Fujii S, Kishi H, Nomura M, Goto E, et al. Phase II study of carboplatin-Paclitaxel combination chemotherapy in elderly patients with advanced non-small cell lung cancer. Jpn J Clin Oncol 2005;35: 188-94.

19. Makrantonakis PD, Galani E, Harper GP. Non-small cell lung cancer in the elderly. Oncologist 2004;9:556-60.

20. Rama R. Statistical Assistant, PBCR. Population based cancer registry, Chennai Cancer Institute (wia), Adyar, Chennai: Individual Registry Data: 1990-1996.

21. Repetto L, Mammoliti SC. Life expectancy, comorbidity and quality of life: The treatment equation in the older cancer patients. Crit Rev Oncol Hematol 2001;37:147-52.

22. Goldberg RM, Fisch TI, Bleiberg H, De Gramont A, Tournigand C. Pooled analysis of safety and efficacy of oxaliplatin plus fluorouracil/leucovorin administered bimonthly in elderly patients with colorectal cancer. J Clin Oncol 2006;24:4085-91.

23. Yancik R. Cancer burden in the aged: An epidemiologic and demographic overview. Cancer 1997;80:1273-83.

24. SEER Cancer Statistics Review, 1975-2003.

25. Silliman RA, Guadagnoli E, Weitberg AB, Mor V. Age as a predictor of diagnostic and initial treatment intensity in newly diagnosed breast cancer patients. J Gerontol March 1989;44:M46-50.

26. Smith BD, Haffty BG, Hurria A, Galusha DH, Gross CP. Postmastectomy radiation and survival in older women with breast cancer. J Clin Oncol 2006;24:4901-7.

27. Talarico L, Chen G, Pazdur R. Enrollment of elderly patients in clinical trials for cancer drug registration: A 7-year experience by the US Food and Drug Administration. J Clin Oncol 2004;22:4626-31.

28. Turner NJ, Haward RA, Mulley GP, Selby PJ. Cancer in old age: Is it inadequately investigated and treated? BMJ 1999;319:309-12.

29. WHO, Geneva. National cancer control programmes, policies and managerial guidelines. $2^{\text {nd }}$ ed. Geneva: World Health Organization; 2002.

30. Yancik R, Ries LA. Cancer in older persons: An international issue in an aging world. Semin Oncol 2004;31:128-36.

31. Yancik R, Ries LA. Aging and cancer in America, demographic and epidemiologic perspectives Hematol Oncol Clin North Am 2000; 14: 17-23.

32. Yancik R, Ganz PA, Varricchio CG, Conley B. Perspective on comorbidity and cancer in older patients: Approaches to expand the knowledge base. J Clin Oncol 2001;19:1147-51.

33. Lichtman MS. Guidelines for the treatment of elderly cancer patients. Cancer Control 2003; 10:445-53.

34. Yancik R, Wesley MN, Ries LA, Havlik RJ, Edwards BK, Yates JW. Effect of age and comorbidity in postmenopausal breast cancer patients aged 55 years and older. JAMA 2001;285:885-92.

35. Perpetuo MD, Valdivieso M, Hebrum LK. Natural history, study of gallbladder cancer: A review of 36 years experience at MD Anderson Hospital and Tumor Institute. Cancer 1978;42:330.

How to cite this article: Sarkar A, Shahi UP. Assessment of cancer care in Indian elderly cancer patients: A single center study. South Asian J Cancer 2013;2:202-8.

Source of Support: Nil. Conflict of Interest: None declared. 